Published in final edited form as:

Annu Rev Genomics Hum Genet. 2010 September 22; 11: 361-381. doi:10.1146/annurevgenom-082509-141711.

\title{
INFORMED CONSENT IN GENOMICS AND GENETIC RESEARCH
}

\author{
Amy L. McGuire ${ }^{1, *}$ and Laura M. Beskow ${ }^{2}$ \\ ${ }^{1}$ Center for Medical Ethics and Health Policy, Baylor College of Medicine, Houston, Texas \\ ${ }^{2}$ Duke Institute for Genome Sciences \& Policy, Center for Genome Ethics, Law \& Policy, Duke \\ University, Durham, North Carolina
}

\begin{abstract}
Informed consent is a cornerstone of the ethical conduct of research involving humans. Based on the ethical principle of respect for persons (67), the goal of informed consent is to ensure that subjects are aware of the risks and potential benefits and make a voluntary decision about participating in the research (67). However, advances in genetic and genomic research--in particular, the increasing emergence of large-scale population studies and genomic databases--have challenged traditional conceptions of informed consent $(18,40)$.
\end{abstract}

Genetic and genomic research requires access to human DNA from biological specimens, which can be stored and used in multiple research studies. Access to stored biospecimens for genetic and genomic research is critical because understanding genetic variation and its association with common and complex disorders on a genome-wide scale requires large sample sizes to achieve sufficient power (101). Biospecimens are most useful when linked to clinical and other phenotypic information about the sample source. This has been accomplished in some countries by the creation of national biobanks (98). In addition to the proliferation of population-based biobanks, many investigators, pharmaceutical companies, and institutions are collecting and storing biological specimens, clinical data, and genetic information in local and regional repositories. Often, cell lines are made so that the specimens can be studied indefinitely, and resulting DNA data are made broadly available for secondary analysis through publicly accessible or restricted databases $(38,68,69,70,75$, 93, 102, 103).

How specimens and data are collected and stored, for how long, by whom, and for what purposes varies tremendously. However, most genetic and genomic research projects share several common features that challenge the established norms of informed consent (Table 1). In this article, we discuss these challenges, explore specific elements of informed consent for genetic and genomic research, and consider alternative consent models that have been proposed (Table 2). All of these models attempt to balance the obligation to respect and protect research participants with the larger social interest in advancing beneficial research as quickly as possible.

\section{The Challenge of Informed Consent for Genetic and Genomic Research}

Traditional standards of informed consent require, with limited exceptions, that subjects enter into research voluntarily and with sufficient information about the research activity to make a comprehending decision about participation (118). Yet, the storage and broad sharing of biospecimens and data make it impossible to describe in detail or even to foresee all of the future research for which they might be used at the time they are collected. Further, because technology is advancing at such a rapid pace, the future risks associated with

Please direct correspondence to: Amy L. McGuire, JD, PhD, Center for Medical Ethics and Health Policy, Baylor College of Medicine, One Baylor Plaza, MS 420, Houston Texas 77030, Phone: 713-798-2029, Fax: 713-798-5678, amcguire@bcm.edu. 
research using biospecimens and data are unpredictable. Therefore, legal and ethical requirements of informed consent for all future uses cannot be satisfied at the time biospecimens and data are collected. Even so, most would agree that stored specimens and data are a valuable resource and should be used to advance research if appropriate protections are in place. Several alternative approaches to consent for genetic and genomic research have been proposed to address this inherent tension.

All of these approaches recognize that research involving human biological materials consists of two distinct steps: (a) the collection and storage of specimens and data; and (b) the use of stored specimens and data for research. With regard to Step 1, specimens and data may be collected as part of a primary research study and then kept for other uses, or they may be collected and stored as part of an independent effort to build a "biobank." In either case, establishing a repository of specimens and/or data intended for future use-although not a 'study' per se-is a research activity. As such, it must comply with research ethics norms and in the United States it must satisfy federal regulations concerning the protection of human research subjects $(114,116,117,118)$. In many cases, these regulations require researchers to have an Institutional Review Board (IRB)-approved protocol and to obtain participants' informed consent specifically for this banking activity. During the informed consent process, prospective participants can be given comprehensive information about the repository (i.e., the collection of stored materials) itself, including details concerning its purpose, procedures, confidentiality protections, risks, and benefits.

More challenging is the issue of how best to approach consent for Step 2: the use of stored specimens and data in research. Traditional consent models would suggest that because all of the relevant information about the future research that will be conducted is not available at the time of initial consent, researchers should re-contact participants to obtain specific consent for each additional use. However, this approach raises significant concerns about the impact on research participants and the research enterprise alike.

For participants, repeated contact—potentially over decades—-to obtain consent for each study using their specimen may be seen as an unwelcome intrusion and a disincentive to participation. An additional concern is the possibility that, with each contact, participants may come to erroneous conclusions about why their specimens have been selected for the study of a particular gene or condition $(11,41)$.

With regard to the research enterprise, strict adherence to traditional consent standards may threaten the viability of many otherwise beneficial studies. Requiring specific consent for each research use could entail significant costs and delays, and could have an adverse effect on validity due to non-response and loss to follow-up $(42,94)$.

In the sections that follow, we first discuss the specific informational elements that should be included in consent documents when collecting and storing human biological specimens for use in genetic and genomic research. We then explore alternative models of consent for the research use of stored specimens and/or data.

\section{Informed Consent for the Collection and Storage of Biospecimens and Data}

Although the collection and storage of biospecimens is typically thought to involve minimal risk, considerable information must be conveyed during the informed consent process, some of it complex or controversial (12). Examples include the use of biospecimens and data in future research unspecified at the time of consent; indefinite storage; ongoing medical record access; contact for future research; large-scale data sharing; development of commercial products; privacy and confidentiality protections; access to individual and aggregate research results; and the ability to withdraw consent. 
In this section, we explore these and other topics in the context of the major elements that should be included in consent forms for genetic and genomic research. Although we believe that each of these elements is important to discuss during the informed consent process, we are cognizant of the fact that lengthy consent documents can be confusing and counterproductive. There is therefore a need to develop simplified consent documents that facilitate informed decision-making (12). The specific language that is appropriate for each research activity will vary, but some uniformity will facilitate sharing and maximize the scientific utility of samples and data.

\section{Purpose}

Consent documents should contain a statement that the project involves research and an explanation of the purposes of the research (118). For projects involving the collection and storage of biospecimens and data, this would typically include a statement that stored materials will be used in future research, a brief description of the underlying genomic science, the disease(s) or condition(s) that may be studied, and the immediate and long-term goals of the project (71).

A significant challenge for investigators is how to craft this language so that the information is sufficient to allow prospective participants to make an informed decision and yet avoid unduly restricting future research. Consent is meaningful only if participants appreciate, as much as possible, the kinds of studies that may be conducted (64). At the same time, providing detailed information may be burdensome and uninformative, as well as lead to ambiguities about whether particular studies are consistent with the precise description participants were given (65). As stated by Wendler and Grady, "Investigators do not need to disclose, and potential participants do not need to understand all there is to know about research. Not only is there too much to know, but much of what there is to know is not necessary to give valid informed consent" (110). Some have proposed using the standard of what a 'reasonable volunteer' would want to know $(67,94)$, suggesting the potential value of empirical research in this area.

Below is one example of language describing the purpose of a biobank. In a study of informed consent for this particular project (81), validated measures of objective and subjective understanding (50) indicated that the nature and purpose of the research were among the best understood domains:

Northwestern University has created a genetic bank. A genetic bank is a collection of blood-based samples, such as DNA and RNA, and health information from many people. The genetic samples and health information will be shared with researchers for future research about the role genes play in human diseases (77).

\section{Procedures}

It is important for prospective research participants to understand what they will experience if they agree to take part (71). Describing the procedures as sequential steps may make the information easier to understand; for example (10)

1. We will get a blood sample from you.

2. We will get some information about you and your health.

3. We will store your sample and information in the Biobank.

4. We will let researchers use the materials stored in the Biobank for approved studies.

5. We may contact you in the future with offers to take part in other research. 
6. Some of your genetic and health information may be placed in scientific databases.

Additional details about each of these topics are provided below.

Biospecimen collection-Participants must be informed about the procedures that will be used to obtain biological specimens. When biospecimens for research will be collected during a clinical procedure, participants should be told whether extra tissue (beyond what is needed for their medical care) will be obtained or if researchers will only use any tissue remaining after medical tests have been completed.

Due to increasing scientific interest in the development of molecularly targeted drugs, biospecimens are sometimes collected by asking clinical trial participants to undergo additional research biopsies beyond that needed for their care $(2,16,43)$. Undertaking biopsies solely for research raises a number of concerns but, as stated by Helft, "Whether it is ethical or not for a patient to give something of value (the biopsy) and receive nothing of benefit in return hinges on the voluntary nature of the giving and the patient's ability to provide meaningful informed consent" (43).

Information collection-Genetic and genomic research may involve collection of three broad types of information, which should be described during consent processes as applicable. First, researchers might ask participants to fill out a questionnaire with personal information such as age, sex, race/ethnicity, and personal and family health history. Participants should be informed about plans for future contact to update this information. Second, researchers might wish to collect clinical information by accessing participants' medical records. Consent forms should describe the kinds of information that will be collected and whether the collection is one-time or ongoing. Finally, some biospecimen collections may ask researchers, as a condition of using the stored materials, to return research data (e.g., genotypes, results of biochemical analyses) so they can be integrated into the collection.

Storage-Consent processes should include a brief description of how and where specimens and information will be stored. Best practice guidelines recommend that stored materials be labeled with a unique code not derived from information about the subject (48), and this practice should be conveyed to participants. Participants should also be informed about duration of storage, e.g.,

There is no limit on the length of time we will keep your blood and information. We will keep them as long as they are useful, unless you decide to stop taking part or we close the Biorepository (11).

Researcher access-According to best practice recommendations (65), biospecimen resources should establish guidelines for sample distribution and clinical data sharing that are consistent with ethical principles, governing statutes and regulations, and, if applicable, informed consent language. These procedures for how requests to study the stored materials will be evaluated should be conveyed to participants, including descriptions of:

- Scientific review of proposed studies

- Ethics review of proposed studies (e.g., review by the biospecimen collection's IRB, the researcher's IRB)

- The types of researchers (e.g., academic, industry, government) that will be permitted to access the materials and whether researchers from other countries will be allowed access 
Recontact-There are several reasons researchers might want to recontact participants- to update their personal information, to ask for another biospecimen if the first has been depleted, to request participation in another study—and these possibilities should be communicated during the consent process.

With regard to the latter, best practice guidelines suggest that consent documents provide an option for participants to select whether or not they are willing to be recontacted about future research (65). Indeed, there is some evidence to suggest that, although many people who agree to participate in a biorepository are amenable to contact about additional research, others are concerned about excessive contact and lack of benefit (11). Thus, consent documents should clearly describe how often such contact might occur (e.g., "up to three times a year") and outline the process by which such contact will occur (71).

An emerging area of interest is genotype-driven recontact, meaning assembling a case group comprised of individuals who have a particular genotype and performing hypothesis-driven "targeted phenotyping" among these cases and a randomly selected group of controls who do not bear the gene variant of interest (59). With regard to consent, one suggestion is that, when recontacted, participants should be told that the follow-up study is genotype-driven and what that means, what the genotype and biological pathway of interest is, that half of the participants are controls with no particular genetic variation, and that an invitation to participate is not contingent on the presence of any known phenotype (59).

Large-scale data sharing-A distinguishing characteristic of genomic research is that it generates large datasets of genomic and health information that is increasingly being deposited into centralized databases for sharing with the broad biomedical research community (71). This kind of sharing is governed by procedures associated with the database; for example, NIH's database of Genotypes and Phenotypes (dbGaP) uses a controlled access approach that is mediated through a Data Access Committee (72). Because such sharing is not under the direct control of the original biospecimen resource and may involve different access policies than those described for the resource itself, large-scale sharing should be explicitly described during the consent process.

In addition to making it clear that large-scale sharing will occur, other sections of the consent document-including potential benefits, risks, return of results, privacy and confidentiality protections, withdrawal of consent, and commercial use-should be consistent with the policies and procedures that will apply under large-scale sharing. Submission of data to dbGaP, for example, requires that the investigator's IRB verify that such submission and subsequent sharing are consistent with the original consent document signed by research participants from whom the data were obtained (74).

\section{Risks and Benefits}

A description of any reasonably foreseeable risks or discomforts to the subject, as well as a description of any reasonably expected benefits to the subject or to others are basic elements of informed consent (118).

Requesting general consent for the collection and storage of biospecimens and data for future research relies on altruism; because the future research is undefined, participants must accept the risks involved with the hope of helping to further biomedical research, rather than the expectation of any direct benefit. The operating procedures for biospecimen collections should honor this altruism by having rigorous processes to ensure that samples and data are put to good use, and by devising ways to communicate clearly about the research being conducted and what is being learned (11). 
The physical risks involved in genetic and genomic research are usually minimal. The potential harms associated with research using human biological materials arise from the misuse of information, which could lead to employment or insurance discrimination, stigmatization, psychological harm, and familial disruption. Thus, the extent to which biospecimens and data can be linked to specific individuals is a central component in the assessment of risk. Concern about identifiability recently intensified when it was discovered that genetic data in a pool of data from hundreds of people could be traced back to individuals who had provided their DNA for research $(24,44)$. Previously, such aggregate datasets were often widely shared and even posted on public websites because they were thought to disclose negligible information about an individual's participation in a study (49). Although the capacity to identify an individual in an aggregate dataset is currently limited (89), this discovery highlights the constant prospect of unforeseen risks due to rapid technological advances.

Consent processes should be designed to communicate clearly about the risks associated with inappropriate disclosure of private information. These risks should be discussed in terms of the likelihood of such disclosure occurring, as well as the probability and magnitude of the harm that could realistically result (64). Confidentiality should not be guaranteed and participants should be informed that there may be some risks that cannot be foreseen.

Finally, because genomic research is expected to identify disease-associated gene variants that vary in frequency between populations, the results of some studies could be used to exacerbate existing stereotypes and potentially stigmatize all members of a socially-defined group (e.g., by race or ethnicity) (8). Some have suggested that such risks should be disclosed to individuals during the consent process so that they can incorporate this information into their decisions (51). Others have suggested that rather than, or in addition to, disclosing these risks, they should be addressed during the research design phase through a process of community engagement (107).

\section{Protecting Privacy and Confidentiality}

Protecting the privacy of individuals who contribute specimens for genetic and genomic research and maintaining the confidentiality of associated health information and research data is critical - as an ethical obligation and for the success of the repository. Researchers have everything to gain from implementing robust protections which, in turn, may create an atmosphere of confidence and encourage recruitment and retention (28).

Biospecimen collections should establish clear policies and procedures for protecting identifiable information, which may include data encryption, coding, establishing limited access or varying levels of access to data by those associated with the collection, use of nondisclosure agreements, and use of an honest broker system (65). A description of these protections is a required element of informed consent (118).

Two mechanisms for enhancing privacy and confidentiality that have received recent attention include Certificates of Confidentiality and the Genetic Information NonDiscrimination Act.

Certificates of Confidentiality are issued by agencies of the federal government to protect identifiable research information from forced disclosure in any legal proceeding (73). By protecting researchers and institutions from being compelled to disclose information that would identify research participants, Certificates are intended to help achieve the research objectives and promote participation in studies. Certificates are specifically intended for research involving sensitive information, i.e., information that, if disclosed, could have 
adverse consequences for subjects or damage their financial standing, employability, insurability, or reputation (73). NIH has identified "the collection of genetic information" as a sensitive activity, and the role of Certificates has been highlighted in the context of biorepositories (66) and genome-wide association studies (74).

Although commonly believed to offer "nearly absolute privacy protection" (25), it is important to note that the legal authority of a Certificate of Confidentiality to protect an investigator against compelled disclosure has rarely been tested. A recent case suggests that Certificates may not offer full protection, for example in a situation involving a criminal defendant's constitutional right to access information relevant to his defense (10). Thus, caution is warranted in not over-representing the protection a Certificate can offer during the consent process (10). In general, Certificates of Confidentiality cannot replace clear and effective policies for data protection and security, which are essential to the protection of the privacy of research subjects.

The Genetic Information Non-Discrimination Act (GINA) is a Federal law that prohibits discrimination in health coverage and employment based on genetic information (37). More specifically, it prohibits group and individual health insurers from using a person's genetic information in determining eligibility or premiums; it also prohibits employers from using a person's genetic information in making employment decisions such as hiring, firing, promotions, and job assignments (45). It does not prohibit medical underwriting based on current health status, nor does it cover life, disability, or long-term-care insurance (45).

Given that GINA has implications for the actual or perceived risks of genetic research and an individual's willingness to participate in such research, investigators and IRBs should be aware of the protections GINA provides as well as limitations in the law's scope and effect (79). With regard to informed consent, there are two key messages researchers should communicate to prospective participants:

First, they should tell patients that they try to keep information confidential, and so the risks are relatively modest. Then they should tell them that in spite of these efforts, there is still a small chance that breaches of confidentiality and resulting discrimination may happen (111).

In other words, researchers should be careful not to understate or overstate the risks of genetics (88), and also not to imply that confidentiality can be guaranteed.

\section{Costs, Payment, and Commercialization}

Prospective participants should be informed about any costs or payments associated with participation, as well as the possibility that the research could lead to the development of commercial products.

If a biospecimen will be collected for research at the same time as for clinical care, the consent process should clarify participants' responsibilities concerning cost. Payments should be characterized as reimbursement for any expenses, time, or inconvenience, and not as a benefit of participation.

Consent documents and processes should also employ clear and specific language to address the use of biospecimens and/or data by private or for-profit entities, as well as the possibility that research discoveries could lead to the development of tests, drugs, or other commercial products (65). Further, participants should be informed about the allocation of profits generated from such products; for example, the consent document might state that research participants will not share in any profits related to research (66). 


\section{Research Results}

The National Cancer Institute's Best Practices for Biospecimen Resources recommends that "The informed consent document should state whether or not individual or aggregate research results will be released to the human subject, the subject's health care provider, or the subject's family" (65). The simplicity of this recommendation only hints at the complexity of the underlying topic; participant access to research results has been the subject of ongoing debate that ranges between the view that individual results should be offered routinely $(32,33,91,92)$ and the view that such results should seldom if ever be disclosed $(22,62,63,82)$.

Although clinically valid and meaningful results may have a positive impact on an individual's health, providing unvalidated research results can cause stress and anxiety, as well as harms when used for medical or reproductive decision-making (74). A biobanking context adds further complexity, since stored specimens and data can be used in a variety of studies that typically take place without the participant's direct knowledge or consent (13). These studies are often conducted without any interaction with the researcher, who may be unknown to the participant. These characteristics may result in participants perceiving a different stake in the research, and thus having different expectations concerning access to research results.

Current guidelines set a high bar for disclosure-The findings should be scientifically valid and confirmed; the findings should indicate significant risk for a serious health concern (e.g., premature death or substantial morbidity); and proven therapeutic or preventive interventions should be available $(14,64)$.

Thus, with regard to informed consent, a prudent approach may be to proceed with caution but consider "never saying never" with regard to offering individual results (41). At the same time, informed consent processes should be designed to promote understanding of the research purpose of the biorepository and to avoid conflating the role of researchers with that of physicians (7).

Providing access to aggregate study results (e.g., in the form of a newletter or website) is an important way of demonstrating reciprocity with research participants and fostering public trust in and support of the research enterprise $(11,13)$. It is also an important way to make participants' opportunity to withdraw "real." Unless participants are afforded the opportunity to learn about the research being conducted, asking them for general consent cannot be justified based on the notion that they can always withdraw if they object to the research that initially was unspecified.

\section{Withdrawal}

According to federal regulations and ethical principles, research subjects must be allowed to discontinue their participation at any time without penalty or loss of benefits to which they would otherwise be entitled $(114,118)$. In the context of genetic and genomic research in particular, the ability to withdraw is an essential component of the justification for asking participants to provide general consent for the collection and storage of specimens and data when future uses are unspecified (30).

At the same time, withdrawal is complicated by the fact that samples (and accompanying data) from a person's stored specimen may have already been distributed to secondary users who did not collect the original specimen. Current best practice guidelines recommend that participants must be allowed to withdraw the remainder of their specimen, but that samples and data that have been distributed do not necessarily have to be recalled $(29,48,65)$. 
Thus, consent documents and processes should highlight the participant's right to withdraw consent as well as any limits on this right, and provide instructions for how to initiate such a request. Participants who wish to withdraw could be offered a number of options, such as:

- No more contact. The repository would no longer contact the participant (e.g., to update personal information or for additional research recruitment), but would still keep and use the existing specimen and information, as well as access medical records.

- $\quad$ No more access. The repository would no longer contact the participant nor access medical records, but would still keep and use the existing specimen and information.

- Unlink. The repository would permanently destroy the link between specimens and information and identifying information, but would still keep and use the existing (now de-identified) specimen and information.

- No further use. The repository would dispose of remaining specimens and no longer use or update personal medical information.

In response to any request to withdraw, it is theoretically possible to always follow the option of unlinking (removing the person's individually identifiable information from the biospecimens and eliminating private information). This could allow the repository to continue using the specimen and data for research because, once de-identified, such use could be determined not to involve human subjects and thus not require consent $(77,118)$. This approach, however, should be used with caution. The general justification for the use of de-identified samples without consent is that subjects would likely not object and the risks to them are minimal, but this reasoning is difficult to assert when subjects have explicitly indicated their wish to withdraw. Second, the National Bioethics Advisory Commission identified several concerns about "anonymizing" samples, including (64)

- Unlinking samples could compromise the scientific merit of the research

- Unlinking samples reduces, but does not eliminate, the risk of harm to individuals

- Unlinking samples renders further contact with the individual impossible; for example, if something serious about that person's health were discovered

- Even if individuals are not harmed, they have an interest in avoiding uses of their specimens that they regard as morally objectionable

\section{Informed Consent for the Research Use of Stored Specimens and Data}

Conveying the information described in the previous section should facilitate the process of obtaining valid informed consent for the collection and storage of biospecimens and data. A more difficult question is how to approach consent for the research use of stored specimens and data. Any approach must balance the core ethical commitments of respecting research subjects, protecting them from harm, and advancing biomedical research. As noted, strict adherence to a traditional model requiring specific consent for each research use may have significant negative consequences both for research participants and the research enterprise. Traditional consent emphasizes respect for persons, but it may come at a significant cost to research. A range of alternative models have been proposed for how to strike a more appropriate balance, ranging from a model that emphasizes institutional review board oversight and places the decision about the need for consent in its hands, to a donor model, which abdicates the need for consent altogether. 


\section{IRB Determination of Need for Consent}

Under this model, IRB approval and informed consent is required for the collection and storage of samples/data, but no studies take place under the biorepository protocol. Instead, researchers proposing to use the stored specimens and data must submit information about their study to an IRB in a separate protocol and obtain informed consent from participants unless the IRB (or a designated institutional official) determines that the research: (a) does not involve human subjects (45 CFR 46.102(f)); (b) is exempt (45 CFR 46.101(b)); or (c) is not exempt but that the requirement to obtain informed consent can be waived (45 CFR $46.116(\mathrm{c}))$ (118). This approach ensures that each research use of the samples/data is reviewed by an independent board and is determined to be consistent with the ethical norms of research.

Although independent review is a foundational requirement of ethical research conduct, the IRB system is not perfect. IRBs are overburdened and often understaffed (31). In addition, studies have documented inconsistencies in review processes and decision-making among IRBs, even within the same institution $(17,61,95)$. Therefore, individual IRBs may well disagree on whether the research use of stored samples and/or data constitutes research involving human subjects, whether it is exempt from the federal regulations, whether it involves human subjects research but satisfies the requirements for a waiver of consent, or whether informed consent is required.

Research not involving human subjects-A human subject is defined under federal regulation as "a living individual about whom an investigator obtains (1) data through intervention or interaction with the individual, or (2) identifiable private information." (118). Since investigators conducting research using stored samples and/or data do not typically have direct interaction with the participant, the determination of whether they are conducting research involving human subjects turns on the question of identifiability-the degree to which those involved in the research can ascertain the identity of the sources of the specimens and data.

According to the Office of Human Research Protection (OHRP), when investigators using existing biological specimens or data cannot readily ascertain the identity of the research participants (e.g., because the materials are coded and the investigator has no access to the key enabling linkage to identifying information), they are not considered to be conducting human subjects research $(80,114,118)$. However, many have challenged this interpretation of the regulations and argue that research using stored biological specimens and/or DNA data ought to be treated as human subjects research because DNA is itself a unique identifier $(44,54,57)$. Also, coded data had previously been widely interpreted as "identifiable" because somebody could identify the sample by virtue of the code, even if it was not the researcher who was using it (64). This lack of consistency in the interpretation of identifiability persists within the federal government. For example, in order to avoid having to comply with a Freedom of Information Act (FOIA) request to access data in dbGAP (a controlled access database maintained by the NIH), the NIH has determined that the disclosure of DNA data would constitute "a clearly unwarranted invasion of personal privacy" (35). This is clearly in conflict with policy guidance that does not consider coded DNA data to be identifiable under the regulations (56). Finally, there is also a strong argument that, regardless of the potential identifiability of DNA data and the associated privacy risks involved, individuals have an autonomy-based right to determine with whom they want to share their DNA data that ought to be respected through the informed consent process. 
Exempt research-An IRB may determine that even if a research activity involves human subjects it is exempt from federal regulatory requirements for the protection of human research subjects and thus, informed consent for the research activity is not required. There are several categories of research that are exempt, including

Research involving the collection or study of existing data, documents, records, pathological specimens, or diagnostic specimens, if these sources are publicly available or if the information is recorded by the investigator in such a manner that subjects cannot be identified, directly or through identifiers linked to the subject (45 CFR 46.101(b)(4)) (118).

Again, the determination of whether a research activity is exempt turns on the issue of identifiability. Even if an investigator obtains identifiable data, as long as it is already in existence and is either publicly available or recorded in a de-identified manner then the research would be exempt from federal research protection policies. Because specimens are typically stored in a coded manner, IRBs either accept that research using coded specimens does not involve human subjects or they treat all DNA data (even coded data) as identifiable and thus nonexempt research involving human subjects. Many IRBs are shifting to this latter interpretation, but the shift has certainly not been universal, creating confusion and resulting in a lack of uniformity that could potentially impede the ability to share resources.

Waiver of informed consent-If research on stored specimens and DNA data is considered nonexempt human subjects research, then consent for each future study must be obtained unless an IRB waives the requirement for informed consent. In order for a waiver of consent to be granted the IRB must determine:

1. The research involves no more than minimal risk to the subjects;

2. The waiver or alteration will not adversely affect the rights and welfare of the subjects;

3. The research could not practicably be carried out without the waiver or alteration; and

4. Whenever appropriate, the subjects will be provided with additional pertinent information after participation (45 CFR 46.116(d)) (118).

With regard to the second and third criteria, as long as appropriate security measures are in place and the research does not involve traits or conditions that would be viewed by the subject or her community to be highly sensitive or stigmatizing, a waiver of consent should not adversely affect the rights and welfare of subjects. It can also be argued that because of the expense and practical hurdles associated with re-contact, most biobanking research could not practicably be carried out without a waiver of consent. As for the fourth criterion, NBAC concluded that this condition is not usually relevant to research using human biological materials (64).

However, there is some debate about whether research using stored samples and/or data meets the first criterion of involving no more than minimal risk. Some have argued that because the risks are primarily informational, as long as adequate privacy protections have been adopted the research should be considered minimal risk $(6,64)$. Yet, research shows that IRB chairs vary in their assessment of what constitutes minimal risk (108) and tend to be conservative in their judgments (90). A clearer definition of minimal risk in this context would aide researchers and IRBs in their determinations of whether a particular research project using identifiable specimens or data can go forward with a waiver of informed consent. 


\section{Categorical Consent}

Another proposed model for approaching the problem of consent for future research use is to provide subjects with an opportunity during the initial biobanking consent process to decide in what ways and by whom those samples/data can be used $(23,52,64,86,100)$. For example, some participants may only want their specimens and data to be used in research related to a particular disease or condition, such as cancer or epilepsy. Others may object to certain specific uses of their sample/data (e.g., for research on alcoholism or mental illness) or to certain types of researchers (e.g., researchers from commercial industry or from other countries). Providing an opportunity for subjects to control aspects of the research that can be done using their specimens and/or data respects their autonomy and allows them to make general decisions consistent with their values and beliefs. However, this approach requires a significant administrative and financial investment in order to keep track of and act in accordance with each person's individualized decision. There is also the problem of pleiotropy; because a single gene may influence multiple phenotypic traits, it may not be possible to limit the research to identified disease-specific categories.

\section{Blanket Consent}

Emerging arguments call into question the primacy afforded to individual autonomy by existing consent norms, and urge that other values, such as justice, solidarity, altruism, and equity also be taken into account $(20,99,112)$. This has led some to suggest that asking participants to provide "blanket consent" for all future uses of their specimens at the time they are collected might be sufficient to satisfy the legal and ethical requirements for informed consent (42). Some studies suggest that this is consistent with the level of control that at least some participants desire $(105,109)$, and have shown that even when participants are given a menu of options for how their samples and data are used, most agree to either have their specimens used in all future research or none at all (21). However, commentators have questioned how "informed" such consent can be when the future research is unspecified $(18,19,28,40)$. In addition, there is general consternation about potentially weakening appreciation of the core legal and ethical principles that underlie the ethical conduct of research (19). For example, the Nuremberg Code states that "The voluntary consent of the human subject is absolutely essential" (78) and the Declaration of Helsinki notes that "considerations related to the well-being of the human subject should take precedence over the interests of science and society" (113).

\section{Opt-Out}

One way to preserve the right to refuse participation in genetic and genomic research without incurring the burdens of informed consent is through public disclosure and an opportunity to opt out of participation. The opt-out approach has been adopted in other contexts, such as organ donation, and has been successful at increasing the number of individuals who participate in those programs (1). The opt-out option can be implemented at the community level (e.g., by disclosing to the community and providing a phone number for individuals to call to opt out) or at the individual level (e.g., by informing each individual about the research and affording him or her the opportunity to opt out by checking a box on a form or calling a centralized number).

Iceland has implemented a community opt-out process for its population biobank, the Icelandic Helathcare Database. In December 1998, the government of Iceland passed the Health Sector Database Act, which granted a 12-year exclusive license to deCODE genetics, a genomics company located in Iceland, to create a centralized database of the medical records of all Icelandic citizens to be used for research and for commercial purposes (47). After extensive public debate, the law was passed and the database was set up without a requirement for informed consent from Icelanders. Rather, consent was presumed and 
individuals were provided an opportunity to opt-out of participation in the database by signing a form that was made available through all healthcare institutions (96). The opt-out approach was thought to be defensible because of strong public support for the database and the privacy protections afforded by de-identifying the stored data (96). A public poll conducted in April 2000 showed that only $8.6 \%$ of Icelanders objected to the database and only $7 \%$ had opted out (96). Some experts, however, object to the opt-out approach, arguing that it is not legally justified and does not satisfy the requirements for ethical research practice $(3,4)$. In a subsequent legal dispute, the Icelandic Supreme Court determined that opt-out consent was justified because there is no clear precedent for consent for DNA databanks, even though they recognized that the information in the database may be potentially identifiable $(39,85)$.

Several other countries have also created large national biobanks (98), but none have adopted the community opt-out approach. In the United States, at least one institutional biobank has adopted an individual opt-out approach. Vanderbilt University has created a DNA repository, BioVU, which collects discarded blood from all Vanderbilt patients who have not opted out of participation, links it with information from their electronic medical record, runs it through a one-way hash so that it is irreversibly de-identified, and stores it for future research use (87). Patients are informed that their medical record information and residual blood will be stored in the repository and provided an opportunity to opt-out of participation when they sign the standard hospital consent to treat form. A community survey revealed that $90 \%$ of respondents were "comfortable with the idea of anonymized genetic information being used for research," and less than $3 \%$ of patients have opted not to participate (87).

These examples suggest that an opt-out approach to the collection and storage of residual samples and to use of stored specimens in genetic and genomic research may increase participation and seems to be consistent with research showing that a majority of potential participants support these research efforts. It is not clear from existing studies, however, whether those individuals adequately understand that they are participating in research or what the risks and benefits to them might be. It is also unclear whether all of those who might object to the research have sufficient knowledge, sophistication, or opportunity to take advantage of the opt-out protections that are afforded.

\section{No Consent}

Finally, some have argued that any model of consent for research using biological specimens and data impedes scientific advancement and, at the same time, does not adequately protect subjects (99). Even if we concede that the collection and storage of residual samples and the use of stored specimens/data involves human subjects, the argument goes, none of these activities pose more than minimal risk to participants and together they confer a great benefit to society. Hence, there ought to be a social obligation to participate. This rationale, however, assumes a just health care system where all members of society benefit equally from scientific discovery and ignores the autonomy-based rights of subjects to decide with whom to share their personal and private genetic and clinical information.

\section{Participant Perspectives}

Surveys of participant attitudes show general support for the use of stored samples in research (104). Findings indicate that participants want to know about research that is done using their biological specimen $(46,105)$, and some participants think it is necessary to obtain consent for each research use. For example, in a telephone interview with 1,193 patients from several different medical disciplines in five U.S. academic medical centers, 
Hull et al. found that $57 \%$ of respondents who wanted to know about research using their sample would require researchers to seek their permission, while $43 \%$ would be satisfied with notification only (46). Participants in this study wanted to know about the research regardless of whether the samples were identifiable or "anonymized" (46). However, in an earlier study of sample sources' preferences, Wendler and Emanuel found that $66 \%$ of respondents wanted to consent to the use of identifiable samples, but only $27 \%$ wanted to consent if the sample was "anonymized" (109). This suggests that some, but not all, of the desire for re-consent has to do with concerns about privacy. It is not clear, however, whether participants in these studies understood the inability to truly anonymize DNA data.

Participants may want to be asked permission to participate in biobanking research, but studies show that they are generally willing to consent to the collection and storage of residual biological specimens (60) and are likely to grant permission for the use of stored samples, at least after they have been "anonymized" (97). Concerns remain, however, about the integrity of the initial informed consent process (15), and additional research is needed to explore how participants' balance their desire for information and control with their altruistic interest in advancing research (58). Policy in this area must balance participants' preferences with other ethical and practical considerations. When considering participant perspectives, it is essential that not only the views of the majority are taken into account, but that the minority point of view is also considered, especially since those in the minority may come from underrepresented or marginalized racial or ethnic groups (60).

\section{Moving Forward: Consent as an Ongoing Process of Communication}

To summarize, new developments in genetic and genomic research and specifically the establishment of repositories of stored samples and data for future research that cannot be anticipated at the time of collection make it difficult, if not impossible, to satisfy traditional informed consent requirements (18). The alternative approaches discussed above involve the loosening of informed consent requirements in order to facilitate scientific progress. This may be ethically justified as long as research participants are protected via strong security measures and robust governance structures (198 30, 94).

Although re-contacting participants to obtain their specific informed consent for each research use of their sample raises significant concerns, there are many reasons why researchers may want to remain in contact with participants (e.g., to inform them of what research is being done, to collect follow-up information, to recruit them into additional studies, or to inform them of clinically relevant findings). Automated systems have been proposed to facilitate this type of longitudinal relationship with study participants while giving them control over how actively they participate in the two-way exchange of information (53). This approach treats subjects as active "partners' in research, but it involves a non-trivial investment in time and money and it may not be appropriate for all study populations.

Several groups are already working to develop innovative systems for facilitating this type of longitudinal relationship with participants. One of the earlier models was created by First Genetic Trust, a United States biotechnology company (55). First Genetic Trust was designed to allow study participants to extend and/or restrict their permission for the use of their previously collected biological samples and medical or genetic data for new or ongoing research. It was a web-based infrastructure that enabled participants to make decisions about research participation online.

More recently, Private Access, Inc. was developed and has partnered with Genetic Alliance, the world's leading nonprofit health advocacy organization (36), and Pfizer Inc., the world's 
largest research-based pharmaceutical company (83), to create an online community to increase awareness of and participation in clinical trials and genetic research (84). The company aspires to create an online community where members can get current information about relevant research, and researchers can identify and recruit potential participants. PrivacyLayer ${ }^{\mathrm{TM}}$ enables members to set their privacy preferences and to control who may access and use information from their electronic portable health record. In September 2009 Forbes magazine named Private Access, Inc. one of “America's Most Promising Companies" (34).

Over the past several years there has been a proliferation of companies offering genetic testing online directly to consumers. Several of these companies offer genotyping of more than 500,000 genetic variants (single nucleotide polymorphisms, or SNPs) on each individual $(26,76,115)$. At least one company, 23andMe, stores this information and consumers are informed that it will be used for research (115). If consumers would like to participate more actively in research then they can sign up for 23andWe, the research arm of 23 andMe, and make themselves available to be recruited into additional research studies.

Finally, at least one academic group has proposed a collaborative clinical research regime, which would allow researchers and participants to stay in touch and to make informed decisions about ongoing research participation over time (53). Subjects who enroll are given a web-based interoperable personally controlled health record (PCHR) and only the participant can decide with whom and under what conditions to share personal information and biospecimens.

There are several limitations to these interactive approaches. For example, they are only applicable in contexts where all participants have access to a networked computer, (5) and individuals with low health literacy may not be capable of participating (53). They also raise concerns about research validity, as there could be a selection bias among those who are capable of and choose to participate. Providing participants with individualized access to information and control over decision making seems to be consistent with reported preferences, but additional research is needed to determine whether these approaches satisfy those preferences and how they influence decision making.

\section{Conclusion}

Ultimately, a new model of consent is needed if we are to maximize the scientific utility of stored specimens and data. All of the models discussed above attempt to balance the ethical principles of respect and beneficence with the equally important value of advancing research. Early models sought to loosen consent standards in order to facilitate research, but they sacrifice autonomy and may ultimately impede research by preventing extensive linkage of information. This makes it difficult, if not impossible to collect longitudinal data and precludes recruitment into hypothesis-driven studies requiring more targeted phenotyping. Instead, models that incorporate better communication with research participants are needed to honor their altruism, respect their autonomy, and promote trust in the biomedical research enterprise. The partnership model discussed above provides one example of how stakeholders are exploring innovative ways to foster this level of communication with participants while maximizing the utility of stored samples and data.

\section{Acknowledgments}

This paper was supported in part by grants from the NIH-ELSI Program (1R01HG004333 and 1R01HG004853) and from the NIH CTSA (Clinical and Translational Science Award) to Duke University (1UL1RR024128). We thank Jill Oliver and especially Angela Hamaker for their valuable research assistance. 


\section{LITERAURE CITED}

1. Abadie A, Gay S. The impact of presume consent legislation on cadaveric organ donation: a crosscountry study. J Health Econ. 2006; 25:599-620. [PubMed: 16490267]

2. Agulnik M, Oza AM, Pond GR, Siu LL. Impact and perceptions of mandatory tumor biopsies for correlative studies in clinical trials of novel anticancer agents. J Clin Oncol. 2006; 24:4801-7. [PubMed: 17050865]

3. Annas G. Rules for research on human genetic variation- lessons from Iceland. New Engl J Med. 2000; 342:1830-3. [PubMed: 10853009]

4. Arnason V. Coding and consent: moral challenges of the database project in Iceland. Bioethics. 2004; 18:27-49. [PubMed: 15168697]

5. Artizzu F. The informed consent aftermath of the genetic revolution. An Italian example of implementation. Med Health Care and Philos. 2008; 11:181-90. [PubMed: 17638119]

6. Bathe OF, McGuire AL. The ethical use of existing samples for genome research. Genet Med. 2009; 11:712-15. [PubMed: 19745750]

7. Beskow LM, Burke W, Merz JF, Barr PA, Terry S, et al. Informed consent for population-based research involving genetics. JAMA. 2001; 286:2315-21. [PubMed: 11710898]

8. Beskow, LM.; Burke, W. Ethical issues in genetic epidemiology and population genetics. In: Coughlin, SS.; Beauchamp, TL.; Weed, DL., editors. Ethics and Epidemiology. 2. New York: Oxford University; 2009. p. 182-203.

9. Beskow LM, Dame L, Costello EJ. Research ethics. Certificates of confidentiality and compelled disclosure of data. Science. 2008; 322:1054-55. [PubMed: 19008431]

10. Beskow LM, Dame L, Costello EJ. Author reply. Science. 2009; 323:1289-90. [PubMed: 19265003]

11. Beskow LM, Dean E. Informed consent for biorepositories: assessing prospective participants' understanding and opinions. Cancer Epidem Biomar. 2008; 17(6):1440-51.

12. Beskow LM, Friedman J, Hardy C, Lin L, Weinfurt KP. Simplifying informed consent for biorepositories: What do prospective participants most want to know? Journal. 2009 In press.

13. Beskow LM, Smolek SJ. Prospective biorepository participants' perspectives on access to research results. J Empir Res Hum Res. 2009; 4(3):99-111.

14. Bookman EB, Langehorne AA, Eckfeldt JH, Glass KC, Jarvik GP, et al. Reporting genetic results in research studies: summary and recommendations of an NHLBI working group. Am J Med Genet A. 2006; 140:1033-40. [PubMed: 16575896]

15. Bower MA, McCarthy VP, Bartels DM, LeRoy BS. A survey of genetic counselor's strategies for addressing ethical and professional challenges in practice. J Genet Couns. 2002; 11:163-87. [PubMed: 12735294]

16. Brown AP, Wendler DS, Camphausen KA, Miller FG, Citrin D. Performing nondiagnostic research biopsies in irradiated tissue: a review of scientific, clinical, and ethical considerations. J Clin Oncol. 2008; 26(24):3987-94. [PubMed: 18711189]

17. Burman WJ, Reves RR, Cohn DL, Schooley RT. Breaking the camel's back: multicenter clinical trials and local institutional review boards. Ann Intern Med. 2001; 134(2):152-7. [PubMed: 11177319]

18. Caulfield T, Upshur RE, Daar A. DNA databanks and consent: a suggested policy option involving an authorization model. BMC Med Ethics. 2003; 4:E1. [PubMed: 12513704]

19. Caulfield T. Biobanks and blanket consent: the proper pace of the public good and public perception rationales. Kings Coll Law J. 2007; 18:209-26.

20. Chadwick R, Berg K. Solidarity and equity: new ethical frameworks for genetic databases. Nat Rev Genet. 2001; 2:318-21. [PubMed: 11283704]

21. Chen DT, Rosenstein DL, Muthappan P, Hilsenbeck SG, Miller FG, et al. Research with stored biological samples: what do research participants want? Arch Intern Med. 2005; 165:652-55. [PubMed: 15795341]

22. Clayton EW, Ross LF. Implications of disclosing individual results of clinical research. JAMA. 2006; 295:37. [PubMed: 16391213] 
23. Clayton EW, Steinberg KK, Khoury MJ, Thomson E, Andrews L, et al. Informed consent for genetic research on stored tissue samples. JAMA. 1995; 274:1786-92. [PubMed: 7500511]

24. Couzin J. Genetic privacy. Whole-genome data not anonymous, challenging assumptions. Science. 2008; 321(5894):1278. [PubMed: 18772401]

25. Currie PM. Balancing privacy protections with efficient research: institutional review boards and the use of certificates of confidentiality. IRB. 2005; 27:7-12. [PubMed: 16425475]

26. deCODEme. 2009. http://www.decodeme.com/

27. Department of Biomedical Informatics, Vanderbilt University School of Medicine. The eMERGE Network: a consortium of biorepositories linked to electronic medical records data for conducting genomic studies. 2009. https://www.mc.vanderbilt.edu/victr/dcc/projects/acc/index.php/Main_Page

28. Deschênes M, Cardinal G, Knoppers BM, Glass KC. Human genetic research, DNA banking and consent: a question of 'form'? Clin Genet. 2001; 59:221-39. [PubMed: 11298677]

29. Eiseman, E.; Bloom, G.; Brower, J.; Clancy, N.; Olmsted, SS. Case Studies of Existing Human Tissue Repositories: "Best Practices" for a Biospecimen Resource for the Genomic and Proteomic Era. Santa Monica, CA: RAND; 2003.

30. Elger BS, Caplan AL. Consent and anonymization in research involving biobanks: differing terms and norms present serious barriers to an international framework. EMBO Rep. 2006; 7:661-6. [PubMed: 16819458]

31. Emmanuel EJ, Wood A, Fleischman AF, Bowen A, Getz K, et al. Oversight of human participants research: identifying problems to evaluate reform proposals. Ann Intern Med. 2004; 141:282-91. [PubMed: 15313744]

32. Fernandez C. Public expectations for return of results--time to stop being paternalistic? Am J Bioethics. 2008; 8:46-48.

33. Fernandez CV, Kodish E, Weijer C. Informing study participants of research results: an ethical imperative. IRB. 2003; 25:12-19. [PubMed: 14569989]

34. Forbes. America's Most Promising Companies 2009. 2009. http://www.forbes.com/entrepreneurs/promising-companies/

35. Freedom of Information Act, PL No. 89-554, 80 Stat. 383. Amended 1996, 2002, 2007

36. Genetic Alliance. 2009. http://www.geneticalliance.org/

37. Genetic Information Nondiscrimination Act of 2008, PL No. 110-233, 122 Stat. 881 (May 21)

38. Genome Canada. Data Release \& Resource Sharing Policy. 2008. http://www.genomecanada.ca/medias/PDF/EN/DataReleaseandResourceSharingPolicy.pdf

39. Gertz R. An analysis of the Icelandic Supreme Court judgment on the Health Sector Database Act. Scripted. 2004; 1:241-258.

40. Greely HT. The uneasy ethical and legal underpinnings of large-scale genomic biobanks. Annu Rev Genomics Hum Genet. 2007; 8:343-64. [PubMed: 17550341]

41. Haga SG, Beskow LM. Ethical, legal, and social implications of biobanks for genetics research. Adv Genet. 2008; 60:505-44. [PubMed: 18358331]

42. Hansson MG, Dillner J, Bartram CR, Carlson JA, Helgesson G. Should donors be allowed to give broad consent to future biobank research? Lancet Oncol. 2006; 7:266-69. [PubMed: 16510336]

43. Helft PR, Daugherty CK. Are we taking without giving in return? The ethics of research-related biopsies and the benefits of clinical trial participation. J Clin Oncol. 2006; 24:4793-95. [PubMed: 17050863]

44. Homer N, Szelinger S, Redman M, Duggan D, Tembe W, Muehling J, Pearson JV, Stephan DA, Nelson SF, Craig DW. Resolving individuals contributing trace amounts of DNA to highly complex mixtures using high-density SNP genotyping microarrays. PLoS Genet. 2008; 4(8):e1000167. [PubMed: 18769715]

45. Hudson KL, Holohan MK, Collins FS. Keeping pace with the times--the Genetic Information Nondiscrimination Act of 2008. N Engl J Med. 2008; 358:2661-63. [PubMed: 18565857]

46. Hull SC, Sharp RR, Botkin JR, Brown M, Hughes M, et al. Patients' views on identifiability of samples and informed consent for genetic research. Am J Bioeth. 2008; 8(10):62-70. [PubMed: 19003716] 
47. Icelandic Parlem., the Alpingi. Act on a Health Sector Database. 1998.

48. International Society for Biological and Environmental Repositories. 2008 best practices for repositories: collection, storage, retrieval, and distribution of biological materials for research. Cell Preserv Technol. 2008; 6:5-58.

49. Jacobs KB, Yeager M, Wacholder S, Craig D, Kraft P, Hunter DJ, Paschal J, Manolio TA, Tucker M, Hoover RN, Thomas GD, Chanock SJ, Chatterjee N. A new statistic and its power to infer membership in a genome-wide association study using genotype frequencies. Nat Genet. 2009 Oct 4. [Epub ahead of print].

50. Joffe S, Cook EF, Cleary PD, Clark JW, Weeks JC. Quality of informed consent: A new measure of understanding among research subjects. J Natl Cancer Inst. 2001b; 93:139-47. [PubMed: 11208884]

51. Juengst ET. Group Identity and Human Diversity: Keeping Biology Straight From Culture. Am J Hum Genet. 1998; 63:673-77. [PubMed: 9718361]

52. Knoppers BM, Laberge CM. Research and stored tissues: persons as sources, samples as persons? JAMA. 1995:1806-7. [PubMed: 7500515]

53. Kohane IS, Mandl KD, Taylor PL, Holm IA, Nigrin DJ. Reestablishing the researcher-patient compact. Science. 2007; 316:836-37. [PubMed: 17495156]

54. Lin Z, Owen AB, Altman RB. Genomic research and human subject privacy. Science. 2004; 305:183. [PubMed: 15247459]

55. Manasco PK. Ethical and legal aspects of applied genomic technologies: practical solutions. Curr Mol Med. 2005; 5:23-28. [PubMed: 15720267]

56. McGuire AL. Identifiability of DNA data: the need for consistent federal policy. Am J Bioethics. 2008; 8:75-76.

57. McGuire AL, Gibbs RA. No longer de-identified. Science. 2006; 312:370-71. [PubMed: 16627725]

58. McGuire AL, Hamilton JA, Lunstroth R, McCullough LB, Goldman A. DNA data sharing: research participants' perspectives. Genet Med. 2008; 10:46-53. [PubMed: 18197056]

59. McGuire SE, McGuire AL. Don't throw the baby out with the bathwater: enabling a bottom-up approach in genome-wide association studies. Genome Res. 2008; 18:1683-85. [PubMed: 18974262]

60. McQuillan GM, Pan Q, Porter KS. Consent for genetic research in a general population: an update on the national health and nutrition examination survey experience. Genet Med. 2006; 8:354-60. [PubMed: 16778597]

61. McWilliams R, Hoover-Fong J, Hamosh A, Beck S, Beaty T, Cutting G. Problematic variation in local institutional review of a multicenter genetic epidemiology study. JAMA. 2003; 290:360-6. [PubMed: 12865377]

62. Meltzer LA. Undesirable implications of disclosing individual genetic results to research participants. Am J Bioethics. 2006; 6:28-30.

63. Miller FA, Christensen R, Giacomini M, Robert JS. Duty to disclose what? Querying the putative obligation to return research results to participants. J Med Ethics. 2008; 34:210-13. [PubMed: 18316466]

64. National Bioethics Advisory Commission (NBAC). Research Involving Human Biological Materials: Ethical Issues and Policy Guidance. Vol. 1. Rockville, MD: NBAC; 1999.

65. National Cancer Institute. Best Practices for Biospecimen Resources. 2007. http://biospecimens.cancer.gov/global/pdfs/NCI_Best_Practices_060507.pdf

66. National Cancer Institute. Office of Biorepositories and Biospecimen Research. Custodianship and Ownership Issues in Biospecimen Research. 2007. http://biospecimens.cancer.gov/global/pdfs/CaOSumm.pdf

67. National Commission for the Protection of Human Subjects of Biomedical and Behavioral Research. The Belmont Report: Ethical Principles and Guidelines for the Protection of Human Subjects of Research. Washington, DC: Dep. Health Educ. Welfare; 1979.

68. National Human Genome Research Institute. NIH-DOE Guidelines for Access to Mapping and Sequencing Data and Material Resources. 1991. http://www.genome.gov/10000925 
69. National Human Genome Research Institute. NHGRI Policy on Release of Human Genomic Sequence Data. 1997. Updated December 2000http://www.genome.gov/10000910

70. National Human Genome Research Institute. Reaffirmation and Extension of NHGRI Rapid Data Release Policies: Large-Scale Sequencing and Other Community Resource Projects. 2003. http://www.genome.gov/10506537

71. National Human Genome Research Institute. Informed consent for genomics research. 2009. http://www.genome.gov/27026588

72. National Institutes of Health. Genome-Wide Association Studies (GWAS). 2008. http://grants.nih.gov/grants/gwas/

73. National Institutes of Health. Certificates of Confidentiality Kiosk. 2009. http://grants.nih.gov/grants/policy/coc

74. National Institutes of Health. Genome-Wide Association Studies (GWAS). NIH Points to Consider. Nov. 2007 http://grants.nih.gov/grants/gwas/gwas_ptc.pdf

75. National Institutes of Health. Implementation Guidance and Instructions for Applicants: Policy for Sharing of Data Obtained in NIH-Supported or Conducted Genome-Wide Association Studies (GWAS). Nov. 2007 http://grants.nih.gov/grants/guide/notice-files/NOT-OD-08-013.html

76. Navigenics. http://www.navigenics.com/

77. Northwestern University. Consent form and authorization for research. https://www.nugene.org/informed_consent.doc

78. Nuremberg Code. Trials of War Criminals before the Nuremberg Military Tribunals under Control Council Law No. 10. Vol. 2. Washington, DC: US GPO; 1949. p. 181-82.

79. Off. Hum.Res. Protection. Guidance on Research Involving Coded Private Information or Biological Specimens. Washington, DC: US Dep. HHS; 2004.

80. Off. Hum.Res. Protection. Guidance on Engagement of Institutions in Human Subjects Research. Washington, DC: US Dep. HHS; 2008.

81. Ormond KE, Cirino AL, Helenowski IB, Chisholm RL, Wolf WA. Assessing the understanding of biobank participants. Am J Med Genet A. 2009; 149A:188-98. [PubMed: 19161150]

82. Parker LS. Rethinking respect for persons enrolled in research. American Society of Bioethics \& Humanities Exchange. 2006; 9:6-7.

83. Pfizer. http://www.pfizer.com/home/

84. PriveAccess. Welcome to Private Access. 2009. https://www.privateaccess.info/

85. Ragnar Guđmundsdóttir v. The State of Iceland. no. 151/2003. http://epic.org/privacy/genetic/iceland_decision.pdf

86. Reilly PR, Boshar MF, Holtzman SH. Ethical issues in genetic research: disclosure and informed consent. Nat Genet. 1997; 15:16-20. [PubMed: 8988163]

87. Roden DM, Pulley JM, Basford MA, Bernard GR, Clayton EW, et al. Development of a largescale de-identified DNA biobank to enable personalized medicine. Nature. 2008; 84:362-69.

88. Rothstein MA. Is GINA worth the wait? J Law Med Ethics. 2008; 36:174-78. [PubMed: 18315769]

89. Sankararaman S, Obozinski G, Jordan MI, Halperin E. Genomic privacy and limits of individual detection in a pool. Nat Genet. 2009 Sep; 41(9):965-67. [PubMed: 19701190]

90. Seema S, Whittle A, Wildond B, Gensler G, Wendler D. How do institutional review boards apply the federal risk and benefit standards for pediatric research? JAMA. 2004; 291:476-82. [PubMed: 14747505]

91. Shalowitz DI, Miller FG. Disclosing individual results of clinical research: implications of respect for participants. JAMA. 2005; 294:737-40. [PubMed: 16091577]

92. Sharp RR, Foster MW. Clinical utility and full disclosure of genetic results to research participants. Am J Bioethics. 2006; 6:42-44.

93. Sherry ST, Ward MH, Kholodov M, Baker J, Phan L, Smigielski EM, Sirotkin K. dbSNP: the NCBI database of genetic variation. Nucleic Acids Res. 2001; 29:308-11. [PubMed: 11125122]

94. Shickle D. The consent problem within DNA biobanks. Stud Hist Philos Biol Biomed Sci. 2006; 37:503-19. [PubMed: 16980191] 
95. Silverman H, Hull SC, Sugarman J. Variability among institutional review boards' decisions within the context of a multicenter trial. Crit Care Med. 2001; 29(2):235-41. [PubMed: 11246299]

96. Stefanson K, Gulcher J. The Icelandic healthcare database and informed consent. New Engl J Med. 2000; 342:1827-30. [PubMed: 10853008]

97. Stegmayr B, Asplund K. Informed consent for genetic research on blood stored for more than a decade: a population based study. BMJ. 2002; 325:634-35. [PubMed: 12242175]

98. Swede H, Stone CL, Norwood AR. National population-based biobanks for genetic research. Genet Med. 2007; 9:141-49. [PubMed: 17413418]

99. Taylor P. When consent gets in the way. Nature. 2008; 456:32-33. [PubMed: 18987719]

100. The American Society of Human Genetics. Statement on informed consent for genetic research. Am J Hum Genet. 1996; 59:471-74. [PubMed: 8755936]

101. The Wellcome Trust Case Control Consortium. Genome-wide association study of 14,000 cases of seven common diseases and 3,000 shared controls. Nature. 2007; 447:661-78. [PubMed: 17554300]

102. The Wellcome Trust. Summary of Principles Agreed at the International Strategy Meeting on Human Genome Sequencing. Bermuda: 1996 February. p.

25-28.http://www.ornl.gov/sci/techresources/Human_Genome/research/bermuda.shtml\#1

103. The Wellcome Trust. Sharing Data from Large-Scale Biological Research Projects: A System of Tripartite Responsibility. Fort Lauderdale: 2003 January 14-15. http://www.genome.gov/Pages/Research/WellcomeReport0303.pdf

104. Treweek S, Doney A, Leiman D. Public attitudes to the storage of blood left over from routine general practice tests and its use in research. J Health Serv Res Policy. 2009; 14:13-19. [PubMed: 19103912]

105. Vermeulen E, Schmidt MK, Aaronson NK, Kuenen M, van Leeuwen FE. Obtaining 'fresh' consent for genetic research with biological samples archived 10 years ago. Eur J Cancer. 2009; 45:1168-74. [PubMed: 19232486]

106. Wagner GP, Kenney-Hunt JP, Pavlicev M, Peck JR, Waxman D, Cheverud JM. Pleiotropic scaling of gene effects and the 'cost of complexity'. Nature. 2008; 452:470-73. [PubMed: 18368117]

107. Weijer C, Emanuel EJ. Protecting communities in biomedical research. Science. 2000; 289:114244. [PubMed: 10970227]

108. Wendler D, Belsky L, Thompson KM, Emanuel EJ. Quantifying the federal minimal risk standard: implications for pediatric research without a prospect of direct benefit. JAMA. 2005; 294:826-32. [PubMed: 16106008]

109. Wendler D, Emmanuel E. The debate over research on stored biological samples: what do sources think? Arch Intern Med. 2002; 98:336-42.

110. Wendler D, Grady C. What should research participants understand to understand they are participants in research? Bioethics. 2008; 22(4):203-8. [PubMed: 18405318]

111. Wilfond BS. The Genetic Information Nondiscrimination Act: fear factor or fantasy island? Hastings Cent Rep. 2008; 38:11-12. [PubMed: 19192707]

112. Williams G, Schroeder D. Human genetic banking: altruism, benefit and consent. New Genet Soc. 2004; 23(1):89-103. [PubMed: 15470784]

113. World Med. Assoc. Declaration of Helsinki: Ethical Principles for Medical Research Involving Human Subjects. Helsinki: 1964. revised Tokyo, Jpn, 1974; Venice, Italy, 1983; Hong Kong, China, 1989; Somerset West, S. Afr. 1996; Edinburgh, UK 2000

114. 21 Code Fed. Reg. Part 50

115. 23andMe. https://www.23andme.com/

116. 45 Code Fed. Reg. Part 160

117. 45 Code Fed. Reg. Part 161

118. 45 Code Fed. Reg. Part 46 
Table 1

Common Features of genetic and genomic research

\begin{tabular}{|ll|}
\hline Common Features of Genetic and Genomic Research & Implications for Informed Consent \\
\hline Indefinite storage and use of biospecimens & Research never ends; consent is forever \\
\hline Unspecified future use & Uncertainty about what participant is consenting to \\
\hline Stability of DNA over time & Privacy risks persist throughout lifetime \\
\hline Broad sharing of samples/data & Uncertainty about privacy risks involved \\
\hline Limited control over downstream access, use, and disclosure & Autonomy rights are limited \\
\hline Limited right to withdraw & Can't change mind; consent is forever \\
\hline Implications for family/community & Group harm \\
\hline
\end{tabular}


Table 2

Consent Models

\begin{tabular}{|ll|}
\hline Consent Model & Type of Consent \\
\hline Human Subjects Model - Traditional & Specific consent with re-contact for each additional use; IRB determination of need for consent \\
\hline Human Subjects Model - Modified & Categorical consent; Blanket consent for all unspecified future research \\
\hline Donor Model & Opt-out consent; No consent \\
\hline Partnership Model & $\begin{array}{l}\text { Ongoing communication with two-way flow of information and continuous opportunity to update } \\
\text { consent }\end{array}$ \\
\hline
\end{tabular}

